\title{
Meesmann corneal dystrophy
}

INSERM

\section{Source}

INSERM. (1999). Orphanet: an online rare disease and orphan drug data base. Meesmann corneal dystrophy. ORPHA:98954

Meesmann corneal dystrophy (MECD) is a rare form of superficial corneal dystrophy characterized by distinct tiny bubble-like, round-to-oval punctate bilateral opacities in the central corneal epithelium, and to a lesser extent in the peripheral cornea, with little impact on vision. 